\title{
As novas tecnologias de informação, comunicação e a educação ambiental
}

\author{
New technologies of information, communication and environmental education
}

\author{
Ana Beatriz Alves de Araújo': Davi Jeremias da Silva Moura², Carlos Enrique de M. Jerônimo³ \\ 'Mestranda do Programa de Pós-graduação em Ambiente, Tecnologia e Sociedade da Universidade Federal Rural do Semi-Árido, Brasil \\ ${ }^{2}$ Especialista em Estratégias de Negócios pela Universidade Potiguar, Brasil \\ ${ }^{3}$ Doutor em Engenharia Quimica Professor da Universidade Potiguar, Brasil
}

\begin{abstract}
Resumo
Nos últimos anos o desenvolvimento das novas tecnologias da informação e comunicação, bem como a ampliação de seus usos têm criado enormes expectativas e possibilidades na educação escolar. Em relação à Educação Ambiental, o uso das novas tecnologias de informação e comunicação representa um avanço no ensino formal, já que a integração da informática e dos multimeios propiciam a sensibilização e o conhecimento de ambientes diferenciados e dos seus problemas intrínsecos, por parte dos alunos, por mais distantes espacialmente que eles estejam. A partir da concepção de uma Educação Ambiental vinculada à pedagogia da complexidade, esse artigo procura discutir a potencialidade do uso dos princípios da Educação Ambiental no suporte digital por meio do uso de imagens, textos e sons, implementados pela hipermídia, tecnologia não sequencial, cujas informações são acessadas de modo associativo. Neste trabalho é apresentada uma correlação entre as novas tecnologias da informação, a comunicação e esses elementos como uma ferramenta para cultuar mudanças no âmbito da educação ambiental.
\end{abstract}

Palavras-chave: Comunicação.Novas tecnologias de informação.Hipermídia. Educação Ambiental.

\begin{abstract}
In recent years the development of new information technologies and communication, as well as the expansion of its uses have created huge expectations and possibilities in education. In relation to environmental education, the use of new information and communication technologies represents an advance in formal education, since the integration of information technology and multimedia provide awareness and understanding of different environments and its intrinsic problems, by students, by spatially more distant they are. From the conception of an Environmental Education linked to the pedagogy of complexity, this article discusses the potential use of the principles of environmental education in digital media through the use of images, texts and sounds, implemented by hypermedia technology not sequential, whose information is accessed associative mode.In this work a correlation between the new information technologies, communication and these elements as a tool for worship changes in environmental education is presented.

regarding the Exploration and Production of Oil that presents the greatest diversity and concentration of risk greater number of workers that industry, in particular with a high percentage of moderate items in the classification adopted.
\end{abstract}

Keywords: Communication. New information technologies. Hypermedia. Environmental Education . 


\section{INTRODUÇÃO}

Nas últimas décadas temos testemunhado o aparecimento de inúmeros movimentos em prol do meio ambiente. Em diversos países, programas e estratégias vêm sendo empreendidas com o intuito de frear a degradação ambiental e/ou de encontrar novas alternativas para processos de produção e consumo menos impactantes.

Dentro desse contexto práticas de Educação Ambiental têm sido intensificadas, tentando sensibilizar e informar as pessoas sobre a realidade ambiental, bem como mostrar e/ou indicar o papel e a responsabilidade da sociedade sobre o que ocorre no meio ambiente.

A expansão da Educação Ambiental tem se dado não apenas pelo crescimento do número de profissionais que tratam do tema, mas também por ter sido incorporada como componente importante em ações de diversas áreas tais como saúde, direitos sociais, gestão ambiental em unidades de conservação e setor industrial, dentre outras.

Ao mesmo tempo, um significativo número de pesquisas e pesquisadores, em várias áreas da ciência, tais como Geografia, Pedagogia, Biologia, Sociologia, tem se referido e se dedicado a projetos de Educação Ambiental, bem como vários países têm demonstrado interesse na sua fomentação, seja pela percepção cada vez maior de seu importante papel preventivo para alguns problemas ambientais, seja pelas exigências de organismos internacionais no sentido da instauração de políticas conservacionistas em que se inclui a Educação Ambiental.

Assim, nos últimos anos, instituições públicas e privadas vêm demonstrando interesse crescente em fomentar a Educação Ambiental, o que tem se dado de vários modos.

Concomitantemente, percebemos uma grande proliferação e abertura de novos espaços de comunicação para a Educação Ambiental, dentre os quais podemos citar fóruns, congressos e, no meio digital, a formação de redes e a multiplicação de sites na internet referentes ao tema, que acabam por sensibilizar a população em geral para os problemas da degradação ambiental.

De fato, os saberes vêm sendo elaborados no transcorrer da história humana, tendo como suporte várias tecnologias de informação e comunicação (TIC), que se modificaram sucessivamente desde o oral, passando pelo meio impresso e atingindo a informatização, o que "[...] não se dá por simples substituição, mas antes por complexação e deslocamento de centros de gravidade" (LÉVY, 1993, p. 10).

A partir, principalmente, da década de 1990, com o advento e popularização da Internet, presenciamos um novo deslocamento nesse "centro gravitacional", o que implica em inúmeras transformações para a vida humana, sobretudo no que diz respeito à circulação do conhecimento e às formas de conhecer. Essas alterações refletem-se, portanto, na nossa compreensão de mundo, no modo de representá-lo, e vêm acompanhadas por uma série de mudanças culturais, presentes no nosso cotidiano, seja no espaço de trabalho, de lazer e/ou de ensino.

No âmbito da Educação Ambiental, percebesse uma intensificação na produção de material pedagógico, audiovisual e/ou impresso, relacionado ao meio ambiente, mas que, contudo, ainda em grande parte não refletem os objetivos explicitados no Programa Nacional de Educação Ambiental e muito menos a realidade socioambiental do lugar, região e país, normalmente tendo uma ótica disciplinar, segmentada, e por vezes tendo como referência apenas valores de determinados segmentos sociais, variando em qualidade e consistência.

Em relação à nova modalidade de materiais didáticos baseados nas novas tecnologias a questão é ainda mais complexa, já que não há uma linguagem ainda estável, devido ao seu pouco tempo de existência o que impede a cristalização de "modelos de sucesso", o que leva realmente a experimentações dos mais variados tipos, como também a uma simples transferência de conteúdos e formas dos meios tradicionais para o meio digital.

Diante desse panorama e considerando o espaço geográfico como instância privilegiada de reprodução das relações de produção da sociedade e, portanto, estreitamente dependente das técnicas utilizadas, consideramos que os Sistemas de Informação Geográfica e a hipermídia têm uma ampla contribuição a oferecer em projetos e pesquisas de Educação Ambiental. Além de o conhecimento geográfico propiciar a conservação do ambiente, suas técnicas possibilitam a construção de mecanismos interpretativos pelos indivíduos onde o território, em nosso contexto histórico atual "[...] inclui obrigatoriamente ciência, tecnologia e informação" (SANTOS, 1997, p.10), favorecendo o seu autoconhecimento como sujeitos sociais atuantes, real ou potencialmente, nos diversos espaços sociais entremeados e superpostos, em direção a uma melhoria da qualidade ambiental e, por conseguinte, de vida. 
Sob essa perspectiva, consideramos que uma das formas que permitem a construção desses processos interpretativos é o uso de materiais didáticos como ferramentas úteis para a construção dos saberes, no caso, ambientais. Nesse sentido, esse artigo procura discutir referências que possam auxiliar na produção de materiais didáticos de Educação Ambiental em suporte digital, buscando-se estabelecer uma correlação entre Educação Ambiental e o uso da hipermídia.

\section{SOCIEDADE DO CONHECIMENTO}

Sociedade da informação, sociedade informacional, da informação e da comunicação, do conhecimento ou alguma outra variação, com as devidas singularidades de significado, são amplamente propaladas a partir dos anos noventas com o desenvolvimento da internet e de outras tecnologias de informação e comunicação.

No entanto, a noção que carregam figura na literatura especializada já há algumas décadas. Castells (2005) lembra, por exemplo, que a internet evoluiu da rede criada pelo Departamento de Defesa dos Estados Unidos (Arpanet) ainda na década de 1960. Em 1973, o sociólogo norte-americano Daniel Bell já fala em "sociedade de informação" no livro O advento da sociedade pós-industrial (BURCH, 2005). Em comum, as expressões que emergem no mesmo contexto têm o fato de considerarem que o conhecimento e a capacidade humana de processamento de informação catalisada pelas novas tecnologias, são o eixo principal da sociedade, em substituição à máquina consagrada na era industrial.

Por novas tecnologias de informação e comunicação (NTICs ou apenas TICs), a propósito, podem ser entendidos todos os aparelhos e tecnologias a eles associados para reunir, distribuir e compartilhar informações (sonoras, visuais ou audiovisuais) bem como para comunicarem-se umas com as outras, individualmente ou em grupo, mediante o uso de computadores e redes de computadores interconectados. Isso significa que as TICs abrangem televisão, rádio, telefone fixo e móvel, projetor de imagem e/ou de som, computador (hardware e software), internet, satélites, tablets, aparelhos compactos de reprodução de imagens e sons, balcões de serviços automatizados (como caixas eletrônicos de banco), correio eletrônico, webcam e microfone entre outros.

Um dos principais teóricos sobre essa temática - que envolve sociedade, cultura, economia, tecnologia -, Manuel Castells entende que, desde o final do século XX, vivemos um raro momento de transformação conduzida por um novo paradigma que se baseia nas tecnologias da informação. Castells (2005) caracteriza o momento atual como "no mínimo, um evento histórico da mesma importância da Revolução Industrial do século XVIII" (p.68). Para ele, "a tecnologia da informação é para esta revolução o que as novas fontes de energia foram para as revoluções industriais sucessivas" (CASTELLS, 2005, p.68).

Resgatando trabalhos de Melvin Kranzberg e Carroll Pursell, Castells (2005) observa que as revoluções tecnológicas são caracterizadas, todas elas, pela penetração que têm em todas as atividades humanas, no tecido social, influenciando mesmo aqueles segmentos que, por uma forma ou outra, mantêm-se ou são mantidos afastados. Ainda que nem todas as instituições e dimensões da sociedade sigam a lógica da "sociedade em rede" (termo amplamente usado por Castells), todas seriam, segundo o autor, em algumas intensidades perpassadas pela "lógica difusa da sociedade em rede", que aos poucos influencia e altera as formas sociais preexistentes.

A característica principal dessa revolução tecnológica, segundo Castells (2005), seria a aplicação do conhecimento e da informação para a geração de novos conhecimentos. As atuais tecnologias seriam mais que ferramentas a serem usadas, seriam processos a serem desenvolvidos. "Usuários e criadores podem se tornar a mesma coisa (...). Pela primeira vez na história, a mente humana é uma força direta de produção, não apenas um elemento decisivo do sistema produtivo" (CASTELLS, 2005, p.69).

Esse autor destaca as oportunidades de ação social que se abrem, sem, no entanto, deixar de reconhecer a "enorme defasagem entre nosso excesso de desenvolvimento tecnológico e o subdesenvolvimento social" (CASTELLS, 2000, p.437). Ao analisar a sociedade em curso sob o contexto do "capitalismo informacional/global", que teria surgido no último quarto do século XX, o autor volta a destacar a simultaneidade do desenvolvimento e subdesenvolvimento econômico, da inclusão e da exclusão social (CASTELLS, 2000). Por exclusão social, entende o "processo pelo qual determinados grupos e indivíduos são sistematicamente impedidos de acesso a posições que lhes permitiriam uma existência autônoma dentro dos padrões sociais determinados por instituições e valores inseridos num 
dado contexto" (CASTELLS, 2000, p.98).

O processo de exclusão, segundo esse autor, atinge pessoas e também territórios, podendo agravar a polarização entre grupos sociais, entre países. Analisando a sociedade dos Estados Unidos no final do século XX, por exemplo, ele observa que muitos dos novos empregos da economia informacional exigem nível educacional e habilidades que raramente as escolas da rede pública têm condições de propiciar (CASTELLS, 2000). Grandes segmentos da população poderiam ser "desabilitados" na sociedade informacional, ao mesmo tempo em que a tecnologia da informação favorece conexões mundiais capazes de aumentar o conhecimento, a mobilização social, o poder de grupos antes desprovidos desse tipo de suporte (CASTELLS, 2000). "O modo de utilização dessas ferramentas e os objetivos de seu uso devem ser prerrogativa exclusiva dos próprios atores sociais em contextos sociais específicos e em nome de seus valores e interesses" (CASTELLS, 2000, p.437).

Enquanto Castells trabalha com a terminologia da "sociedade em rede", dedicando especial atenção à geografia política e econômica na Era da Informação, Pierre Lévy, filósofo francês, é uma importante referência para os estudos das implicações das tecnologias sobre a cultura. Pode-se dizer que as ideias desse autor são complementares às de Castells. Mas, ainda que reconheça o potencial de exclusão da sociedade em rede, com tendência de reforçar os centros tradicionais das diversas modalidades de poder, Lévy é mais otimista em relação às possibilidades de participação abertas pela rede ou ciberespaço. "Algumas das forças atuais ganharão poder, outras irão perdê-lo, enquanto recémchegados começam a ocupar posições que nem mesmo existiam antes da emergência do ciberespaço" (LÉVY, 2000, p.223)

A obra de Lévy é marcada pelos termos "ciberespaço3" e "cibercultura". O primeiro referese tanto à infraestrutura material da comunicação digital quanto ao universo de informações que ela abriga, incluindo-se ainda as pessoas que navegam e alimentam esse universo. Quanto à cibercultura, é entendida pelo autor como o "conjunto de técnicas (materiais e intelectuais), de práticas, de atitudes, de modos de pensamentos e valores que se desenvolvem juntamente com o crescimento do ciberespaço" (LÉVY, 2000, p.17).

O autor propõe o conceito de "inteligência coletiva", que é considerada por ele um projeto que representa a "aspiração mais profunda" da cibercultura. "Não se trata de forma alguma de „utopia tecnológica", mas de aprofundamento de um antigo ideal de emancipação e de exaltação do humano que se apóia nas disponibilidades técnicas de nossos dias" (LÉVY, 2000, p.208). Nesse projeto, não há administrador, todos são responsáveis, não há sujeito submetido, as atividades são espontâneas, descentralizadas. "Estou profundamente convencido de que permitir que os seres humanos conjuguem suas imaginações e inteligência a serviço do desenvolvimento e da emancipação das pessoas é o melhor uso possível das tecnologias digitais" (LÉVY, 2000, p.208).

Esse espaço de acesso, manifestação, interatividade é entendido por Lévy também como alternativa às mídias de massa tradicionais que praticam comunicação unidirecional, com receptores isolados uns dos outros. O ciberespaço, diferentemente, permite que os indivíduos e os grupos sejam autônomos tanto na busca por informações quanto na divulgação de suas versões dos fatos, encorajando "troca recíproca e comunitária" (LÉVY, 2000, p.203).

Na conclusão da obra "Fim de Milênio", volume 3 da coleção A Era da Informação, Castells (2000) é ainda mais comedido, preferindo dizer que "o século XXI não será de trevas", mas "para a maioria das pessoas, também não trará as recompensas prometidas pela revolução tecnológica mais extraordinária da história. Ao contrário, é provável que seja caracterizada por perplexidade consciente" (p.436).

\section{AS NOVAS TECNOLOGIAS DE INFORMAÇÃO E COMUNICAÇÃO}

Definir conceitualmente tecnologia da informação e comunicação é um trabalho árduo, tendo em vista a sua composição por três diferentes conceitos, que possuem várias significações conforme as suas aplicações nas mais variadas áreas do saber humano e de acordo com o contexto histórico em que são utilizados. Uma das formas da resolução desse impasse é tomar conhecimento das conceituações dos três elementos que constituem a tríade tecnologia/informação/comunicação.

Assim, primeiramente, atendo-se ao vocábulo tecnologia, tem-se que as raízes gregas téchne e logos correspondem, respectivamente, à ideia de "arte", "ofício", "indústria" e ao conceito de "palavra", 
"tratado", "estudo", "ciência". Dessa forma, para os filósofos gregos a téchne não era um ofício ou arte qualquer, mas aquela que deveria ser realizada de acordo com o estudo, com a ciência.

De fato, todo o desenvolvimento da relação entre sociedade e natureza se fez pela substituição de uma meio natural por uma técnica, elaborada de acordo com o seu estágio de conhecimento. A noção de técnica adquire um papel tão importante no desenvolvimento das sociedades que Santos (1997) propõe a divisão da história do meio geográfico em três etapas: meio natural meio técnico e meio técnicocientífico-informacional. No meio natural, as técnicas se conciliam com as propriedades da natureza que eram a base material para a existência dos agrupamentos humanos. A partir do Paleolítico Superior técnicas complexas já são adotadas na defesa, alojamento, vestimentas, agricultura, que "[...] não eram agressivos, pelo fato de serem indissolúveis em relação à Natureza que, em sua operação, ajudavam a reconstituir" (SANTOS, 1997, p.188).

No período técnico, a fusão entre técnica e conhecimento será ainda mais ressaltada quando a Enciclopédia Francesa incorpora a técnica à ciência, o que origina a definição da tecnologia como sendo uma técnica que emprega conhecimentos científicos e dá à ciência uma aplicação prática através do uso da tecnologia. Os objetos técnicos juntam à razão natural sua própria razão, uma lógica instrumental que desafia as lógicas naturais, criando, nos lugares atingidos, mistos ou híbridos conflitivos [...]. (SANTOS, 1997, p.189).

Nas sociedades contemporâneas a tecnologia vai ocupando cada vez mais um lugar de destaque na organização das práticas sociais, gerando efeitos em todo o universo social e criando dinâmicas diferenciadas onde o conhecimento passa a tomar um lugar central. De acordo com Santos (1997) essa interação entre ciência e tecnologia se dá de um modo tão intenso, que alguns autores preferem denominá-las com um único conceito - o de tecnociência, enfatizando o seu atual estado de fusão.

Indo além, Santos (1997) propõe que o atual período técnico em que vivemos seja denominado de técnico-científico-informacional tendo em vista que:

A ideia de ciência, a ideia de tecnologia e a ideia de mercado global devem ser encaradas conjuntamente e desse modo podem oferecer uma nova interpretação à questão ecológica, já que as mudanças que ocorrem na natureza também se subordinam a essa lógica (SANTOS, 1997, p.190).

Assim, chegamos ao segundo elemento da tríade - informação, sua raiz latina informare significa "a ação de formar matéria". De acordo com Wurman, até a década de 1940, o conceito de informação é extremamente ligado à "[...] ação de informar; formação ou moldagem da mente ou do caráter, treinamento, instrução, ensinamento, comunicação de conhecimento instrutivo" (WURMAN, 1991, p. 42).

Com o desenvolvimento da informática, o conceito de tecnologias da informação vai paulatinamente abarcando as tecnologias relacionadas à informática, utilizado para transmitir a informação. Deve-se ressaltar que a partir do final da II Guerra Mundial, a informação perde o caráter de elemento(s) que deve $(\mathrm{m})$ levar à redução do grau de incerteza sobre um determinado assunto, passando a ter um significado ligado ao ato comunicante, podendo designar qualquer coisa que fosse comunicada, transmitida, seja ela compreendida ou não.

A partir de então outro elemento passa a ser valorizado e agregado às tecnologias de informação - a comunicação. Importância essa delineada por Schaun, ao declarar que:

A comunicação está em tudo. Tudo é comunicação, transitando num pântano invisível, transparente, entre linguagens, palavras, discursos, sons, fala, imagens, narrativas, abrigando, ainda, a discussão de uma nova dimensão da realidade, propiciada pela velocidade da luz (SCHAUN, 2002, p. 30).

Propondo outro olhar, mais próximo inclusive da concepção grega de técnica, Silva (2002) observa que as Tecnologias de Informação e Comunicação (TICs) estão presentes ao longo de todo o processo de desenvolvimento humano, considerando tecnologia de informação toda configuração comunicativa que utiliza como apoio as tecnologias disponíveis no seu contexto histórico, estando ela, portanto, relacionada à informática ou não. Com o aperfeiçoamento dos microprocessadores, com a digitalização da informação, sua disseminação e popularização, estabelece-se um ajuste estratégico entre o audiovisual, a informática e as telecomunicações, o que resulta na comunicação virtual e nas denominadas novas tecnologias de comunicação e informação.

Desde a década de 1960, o uso das tecnologias de informação e comunicação, dentre elas o computador, têm propiciado também um avanço vertiginoso no armazenamento, manuseio, tratamento e comunicação de informações sobre o espaço geográfico, levando ao desenvolvimento dos 
denominados Sistemas de Informação Geográfica (SIG), os quais acabam por não se conceituar mais apenas nas suas funções sobre o dado manuseado, ou seja, não se restringe às suas potencialidades tecnológicas de estoque de dados geográficos ou de análise e manipulação, mas sim sobre essa atual faceta de nova mídia de dados geográficos e, portanto, de informações geográficas, passíveis de serem utilizadas em Educação Ambiental.

O advento de novas tecnologias de informação e comunicação permitiu que informações antes restritas aos meios acadêmicos e técnicos fossem veiculadas pelas mass mídia, democratizando um pouco mais o acesso a essas informações e favorecendo a reflexão sobre uma nova faceta dos SIGs - o de sua natureza como mídia de informações espaciais, tornando-se um conceito conhecido em várias áreas do conhecimento.

A Web passa cada dia mais a se constituir como um grande canal de divulgação. Primeiramente, voltada à transmissão de informações textuais, posteriormente abrangendo figuras em geral e atualmente, difundindo músicas, fotografias, filmes, mapas, de todas as partes do mundo para todas as partes do mundo. $\mathrm{O}$ uso da internet, como meio de comunicação e informação, realmente acarretou uma verdadeira revolução em termos de tratamento e processamento de todo tipo de informação, inclusive daquela geograficamente espacializada, como em relação à própria concepção de SIG e de cartografia, bem como da forma de conceber, representar e analisar o espaço geográfico.

Apesar de tradicionalmente os cartógrafos sempre tratarem da questão da visualização do dado geográfico nos mapas, atualmente uma atenção maior tem sido dada à questão, já que em alguns casos a comunicação da informação geográfica e, portanto, a sua visualização, pode ser a principal função a ser exigida do mapa.

Tal importância é enfatizada pelas possibilidades que o ambiente digital fornece de linkar material visual diverso e mesmo som com mapas, sendo dado o nome de multimídia a essa possibilidade de comunicação proporcionada pelo uso dos vários meios de representação da informação, como som e imagem animada, além da imagem estática.

A multimídia normalmente é implementada pela hipermídia, tecnologia não sequencial, organizada pelo link de pedaços de informações, em modo associativo, onde o leitor lê o texto de um nó para outro, não o lendo de forma integral, do início ao fim, como um texto impresso, e utilizando diversas mídias, tais como: texto, mapas, gráficos, vídeo, dentre outros.

A tecnologia do hipertexto, portanto, procura de certa forma reproduzir a maneira associativa de organizar as informações, o que foi possível com a criação e melhoramento de uma série de interfaces, tais como os ícones dos programas e a disseminação de seus significados globalmente, o desenvolvimento do mouse que permite a interação do usuário com a tela, a criação dos menus que mostram ao usuário as operações passíveis de serem realizadas e dos programas que permitem a digitalização de músicas e fotos.

A interatividade é o elemento principal dos projetos de hipermídia. Baseando-se na concepção sociológica de interação que remete "[...] à ação recíproca entre dois ou mais atores onde ocorre intersubjetividade, isto é, encontro de dois sujeitos - que pode ser direta ou indireta (mediatizada por algum veículo técnico de comunicação, por exemplo, carta ou telefone)" (BELLONI, 2001, p. 58), designa ora a potencialidade técnica de determinado meio fornecer um determinado nível e quantidade de informação que se quer acessar pelo usuário, de acordo com o seu ritmo e interesse próprios, ora a ação do usuário sobre a máquina e uma resposta da máquina sobre essa ação.

A possibilidade de navegação - acesso a dados variados, de fontes variadas - também é fundamental aos mapas e sistemas interativos, pois fornece informação adicional sobre determinado item quando certas funções são selecionadas, resultando na não linearidade, ou seja, na falta de limitação do usuário a uma dada sequência de informações e de tempo.

Além dessas características específicas, o processo de mudança de suporte das informações para o meio digital acarreta alterações na forma de pensar, que passa a funcionar de modo "tissular (de tecido), em rede, gerando [...] formas de comunicação" (TRAJBER, 2001, p. 17) e de aprendizagem diferentes das tradicionalmente utilizadas, o que implica também em um redimensionamento das relações entre comunicação e educação.

Para Passarelli (1993) o uso de computadores no processo de ensino/aprendizagem tem como base três principais teorias: a Teoria Behaviorista, a Teoria de Sistemas e a Teoria Cognitivista. As primeiras atividades de instrução baseadas no uso do computador, bem como as estratégias tecnológicas utilizadas, que deram origem ao ensino programado foram sustentadas pela Teoria Behaviorista, cujo 
princípio norteador é a atividade instrucional planejada de acordo com os comportamentos desejáveis do aprendiz, os quais devem ser observados e quantificados.

A Teoria dos Sistemas, de modo mais amplo, trata da organização e estrutura dos organismos como um todo. Seus "pressupostos epistemológicos possuem [...] uma concepção interdisciplinar (integradora) da ciência [...] aplicável ao processo educacional com a finalidade [...]" (PONS, 2001, p.59-60) de fazer uma análise e intervenção sobre o sistema denominado "processo educacional".

De acordo com Yildirim (2005), uma das formas de alcançarmos tal propósito é utilizar o computador como uma ferramenta cognitiva, que não apresente apenas a informação, mas também estimule os usuários a acessar, analisar, interpretar e organizar seu conhecimento pessoal a partir de problemas propostos.

Para tanto é de extrema necessidade que um contexto de aprendizagem construtivista seja disponibilizado aos usuários, em que o uso de múltiplos modos de representação e perspectivas, a ocorrência de experiências realistas e relevantes e a consideração das características sociais dos alunos devem ocorrer.

De acordo com Silva, trata-se de fato da construção de um novo paradigma de aprendizagem, onde o processo de aprendizagem consiste no saber interagir com as fontes de conhecimento existentes de outros detentores/processadores do conhecimento, onde o professor adquire um importante papel, uma vez que:

Passar de um conhecimento intuitivo e sumário do senso comum para um conhecimento reflexivo em que o indivíduo seja capaz de organizar, associar e estabelecer relações com as informações não se alcança com a imediaticidade do direto [...] a navegação pelos oceanos informáticos requer a intermediação humana, notadamente a dos professores. [...] A emancipação que a Web proporciona não passa pela supressão dos intermediários, mas antes pelo reconhecimento do seu papel (SILVA, 2002, p. 79).

Tratando-se da Educação Ambiental, o professor deve conseguir problematizar o saber ambiental apresentado no suporte digital, colocando-o em uma perspectiva onde os alunos possam se apropriar e utilizá-lo para a construção das atitudes ecológicas.

Nesse tocante, deve-se ressaltar a distinção entre atitude e comportamento, sendo a primeira um modo de proceder, orientada pelos posicionamentos do indivíduo, enquanto que a segunda, "[...] ações observáveis, efetivamente realizadas, e podem estar ou não de acordo com as atitudes do sujeito" (2004, p.177).

A educação, de fato, sempre se constituiu em um processo de comunicação. Desde tempos remotos da nossa civilização, educação, informação e comunicação sempre caminharam juntas. No modelo tradicional isso se dá por meio da veiculação e divulgação de mensagens verbais e não verbais, de conteúdos curriculares, entre um professor (emissor) e o aluno (receptor). A ação comunicativa de um conteúdo educativo, entretanto, só se dá plenamente quando não se reduz a essa concepção tradicional de transmissão de informações. Com a inserção das novas tecnologias de informação e comunicação na educação, esse modelo passa a ser um fluxo comunicativo onde o aluno se torna também produtor e criador de mensagens, construindo "[...] gradualmente a sua visão de mundo a partir de um conjunto de espaços que hoje trabalham o conhecimento, e a conexão da escola com estes diversos universos, tornada possível pelas novas tecnologias que são essenciais" (DOWBOR, 2004, p.47).

Nesse caso, o uso das novas tecnologias de comunicação com enfoque na Educação Ambiental representa um avanço, já que por meio da integração da informática e dos multimeios pode haver a sensibilização e o conhecimento dos ambientes e dos seus problemas intrínsecos. A virtualidade nesse sentido pode representar um novo esforço na construção e incorporação de conhecimentos ambientais por meio de estratégias mais atrativas de comunicação.

\section{EDUCAÇÃO AMBIENTAL: PRESSUPOSTOS E PRINCÍPIOS}

Um percurso pela história e práticas da Educação Ambiental permite afirmarmos que apesar de ultimamente presenciarmos a publicação de uma série de obras relevantes acerca de Educação Ambiental no Brasil, ainda há certa carência metodológica entre seus praticantes e nos projetos que 
se desenvolvem.

De fato, as ações educativas, dentre elas a construção de materiais didáticos, baseadas nos princípios da Educação Ambiental, devem voltar-se à formação de atitudes ecológicas e cidadãs (CARVALHO, 2004) que pressupõe o desenvolvimento de capacidades e sensibilidades para identificar e compreender os problemas ambientais, mobilizar-se e comprometer-se com a tomada de decisões voltadas à melhoria da qualidade de vida, implicando uma responsabilidade ética/social e justiça ambiental.

Claro que distintas modalidades de ensino requerem metodologias específicas. Entretanto, podemos considerar que alguns pressupostos são básicos e servem de orientação para o encaminhamento de uma prática ambiental, cujas atividades são articuladas pedagogicamente e encontram-se comprometidas com outros processos sociais, apontando claramente as múltiplas e complexas determinações dos problemas ambientais e indicando as formas de ação para combater as suas causas e não apenas os efeitos mais aparentes.

Tendo em mente tais considerações é importante tomar-se como base para a construção do material didático alguns princípios que procuram de algum modo articular informações do conhecimento científico e de experiências técnicas em que ocorre um entrecruzamento bastante complexo, mas necessário, já que as particularidades da temática permitem diversos enfoques, intrinsecamente dependentes das concepções de Educação, Ambiente e Comunicação, bem como da própria postura em relação à inserção das ferramentas tecnológicas na educação.

Até a década de 1950 praticamente não havia nenhuma preocupação com os efeitos ambientais da industrialização. Só em 1952, após uma grande manifestação da incongruência entre as atividades antrópicas contemporâneas e o ambiente, com a morte de 1600 pessoas provocada direta ou indiretamente pelos níveis insustentáveis da poluição atmosférica de Londres, é que uma maior sensibilização coletiva sobre os problemas ambientais ocorrerá, desencadeando "[...] uma série de discussões em outros países, catalisando o surgimento do ambientalismo nos Estados Unidos a partir de 1960" (DIAS, 1991, p.77).

Assim, ao final da década de 1960, o conceito de Educação Ambiental emerge e, em 1971, a primeira definição internacional da Educação Ambiental é adotada pela International Union for the Conservation of Nature (SATO, 2004), ainda essencialmente ligada à questão da preservação de ambientes naturais e dos seus sistemas de vida.

Apenas a partir de 1972, com a Conferência Internacional sobre o Meio Ambiente, em Estocolmo, promovido pela Organização das Nações Unidas (ONU), é que o homem passa a ser considerado como peça chave do processo de conservação ambiental e, de acordo com Sato (1997), a Educação Ambiental vai sendo compreendida de forma mais abrangente. Em 1977, ocorre a I Conferência Intergovernamental de Tbilisi, organizada pela Organização das Nações Unidas para a Educação, a Ciência e a Cultura (UNESCO) com a colaboração do Programa das Nações Unidas para o Meio Ambiente (PNUMA), podendo ser considerada o ponto culminante do Programa Internacional de Educação Ambiental, estabelecido em 1972.

Nessa Conferência é estabelecida a natureza da Educação Ambiental (EA) e definidos seus princípios, objetivos, características, bem como as estratégias a serem adotadas para sua efetivação. A interdisciplinaridade, a perspectiva regional e mundial inter-relacionada e a continuidade passam a ser indicadas como suas características principais. Apesar de se reconhecer que a educação não pode resolver por si só todos os problemas ambientais globais, afirma-se que, com a ajuda da ciência e da tecnologia, pode contribuir para a formulação de outras soluções que visem uma nova ordem internacional, onde o crescimento econômico seja controlado e haja uma distribuição equitativa dos benefícios do progresso.

Estavam, assim, plantados os princípios e características da Educação Ambiental, cabendo a cada país, de acordo com suas peculiaridades socioambientais, definir as linhas de atuação nacionais, regionais e locais. Em 1992, a Conferência das Nações Unidas sobre o Meio Ambiente e Desenvolvimento (CNUMAD/UNCED), realizada no Rio de Janeiro, também denominada de RIO-92, ECO-92 ou Cúpula da Terra, promove discussões que culminam em novas concepções sobre as formas de se conhecer as questões ambientais.

Juntamente com a Carta da Terra elaborou-se o "Tratado de Educação Ambiental para Sociedades Sustentáveis e Responsabilidade Global", documento de apoio para a Educação Ambiental, 
que a reconhece como "[...] um processo de aprendizagem permanente, baseado no respeito a todas as formas de vida" (SATO, 2004, p. 17). Além disso, afirma o seu papel estimulador à formação de sociedades socialmente justas e ecologicamente equilibradas, o que requer responsabilidade individual e coletiva em níveis local, nacional e planetário, enfatizando o seu caráter político, no sentido de estar baseada em valores que devem se orientar para a transformação social.

A orientação da Educação Ambiental para a sustentabilidade tem sido, portanto, crescentemente enfatizada e é objeto de análises de diversos pesquisadores, dentre os quais se destaca Leff (2002), para o qual o discurso do desenvolvimento sustentável não é homogêneo, exprimindo as diferentes visões que se têm correspondentes aos diversos interesses da sociedade, indo desde a perspectiva neoliberal até propostas decorrentes das "novas racionalidades produtivas".

As questões ambientais, portanto, implicam em levar em consideração a complexidade dos sistemas envolvidos, a multiplicidade de seus componentes (físicos, químicos, biológicos, ecológicos, humanos e sociais), a não-linearidade dos fenômenos subjacentes, e, sobretudo, a estrutura espacial e as diferentes escalas espaciais e temporais de suas causas e efeitos.

Dessa forma a investigação das questões ambientais implica na necessidade do enfoque interdisciplinar, mobilizando em diferentes graus de intensidade todas as disciplinas. Isso pode e deve levar à integração de processos naturais e sociais de diferentes ordens de materialidade e esferas de racionalidade e à formulação de novas estratégias conceituais para a construção, sob o enfoque emancipatório, de uma nova ordem teórica que questione a atual racionalidade econômica e processos de produção.

Assim, apesar da interdisciplinaridade ser um ponto de referência constante nos projetos de Educação Ambiental, não significa que pesquisas monodisciplinares não possam ser efetuadas, já que a generalização integrativa dos processos socioambientais é muitas vezes insuficiente para a construção de metodologias interdisciplinares de pesquisa.

Assim, as práticas de Educação Ambiental devem se vincular a uma pedagogia da complexidade, onde existe espaço para a mono, inter e transdisciplinaridade, a fim de se "[...] induzir e fomentar as capacidades e habilidades mentais para ver o mundo como sistemas complexos, para compreender a causalidade múltipla, a interdeterminação e interdependência dos diferentes processos" (LEFF, 2002, p. 250), estimulando o pensamento crítico, participativo e propositivo dos educandos e da comunidade, sendo que esse impulso ao saber ambiental crítico deve se dar por vários espaços de comunicação e com apoios tecnológicos diferenciados.

\section{REFLEXÕES FINAIS}

A crise ambiental no mundo reflete os modelos contemporâneos constituídos de sociedade e de produção/consumo, resvalando em uma crise sobre o conhecimento científico e as disciplinas tradicionalmente constituídas, criando ao mesmo tempo a necessidade de novos saberes e conhecimentos. As diferentes tecnologias implicam mudanças nas atitudes, valores e comportamentos, nos processos mentais e perceptivos, demandando novos métodos educacionais e racionalidades pedagógicas sintonizadas com as necessidades das novas gerações, já que o processo educacional é um ato comunicativo e se não há sintonia não há comunicação.

Considerando essa perspectiva, nosso estudo procurou discutir aspectos relacionados à interação entre Educação Ambiental e hipermídia, já que o desenvolvimento daquela também necessita de materiais didáticos ajustados ao seu tempo tecnológico.

Retomando as nossas colocações iniciais, pressupomos que os materiais didáticos são ferramentas úteis para a construção de saberes ambientais especializados, sendo que os mapas interativos possibilitam inúmeras formas de apresentação dos dados, fazendo com que os usuários possam ficar mais instigados com o conteúdo, auxiliando na visualização dos dados espaciais de modo mais próximo aos atuais hábitos perceptivos da comunidade escolar, imersa no mundo multimídia, confirmando o importante papel do SIG como uma nova mídia a ser utilizada na comunicação da informação geográfica.

Consideramos, ainda, que apesar de uma série de documentos, nacionais e internacionais, definirem os conceitos, características e princípios necessários para o desenvolvimento da Educação Ambiental, o enfrentamento da temática ambiental, no ensino ainda padece de uma orientação mais definitiva. 
Consideramos que a produção de um material didático que possa auxiliar a intervenção docente no sentido da construção de uma Educação Ambiental participativa e emancipatória, não está relacionada com a inserção pura e simples do lúdico ou da percepção da hipermídia como uma ferramenta cognitiva, mas sim com a forma como ela se integra a um processo de reflexão sobre o conteúdo apresentado e aos interesses do usuário.

Dessa forma, o conteúdo visual, a música e o compartilhamento das informações entre alunos professores que a hipermídia pode propiciar, devem ser um motor propulsor para a sensibilização e a identificação dos problemas ambientais, levando reflexão sobre a urgência da mudança dos atuais padrões de uso e distribuição dos bens ambientais.

Além disso, deve-se lembrar de que os professores possuem formas próprias de entender as temáticas ambientais e de implementar o seu tratamento didático com os alunos, sendo a hipermídia uma nova estratégia educacional que pode propiciar uma inovação na sua prática didática cotidiana.

Finalmente, ressaltamos que para uma hipermídia ser realmente uma ferramenta cognitiva deve haver um ambiente contextualmente rico de aprendizagem que dê suporte aos estudantes. Apesar de poder ser projetada com o objetivo de estimular, sensibilizar o aluno à temática ambiental, a hipermídia é um programa que pode somente informar, não ocorrendo à aprendizagem pelo projeto em si, mas pelo uso que se faz por meio dela.

\section{REFERÊNCIAS}

BELLONI, Maria Luiza. Educação à Distância. 2. ed. Campinas: Autores Associados, 2001.

BURCH, Sally. Desafios de palavras: enfoques multiculturais sobre as sociedades da informação. Coordenado por Alain Ambrosi, Valérie Peugeot e Daniel Pimienta, 2005, por C \& F Éditions. Disponível em: <http://vecam.org/article519.html>. Acesso em: 19 jan. 2013.

CASTELLS, M. Fim de milênio: a era da informação, economia, sociedade e cultura. Tradução de Klauss Brandini Gerhardt e Roneide Venâncio Majer. 2. ed. São Paulo: Editora Paz e Terra, 2000. v. 3, 497p.

CASTELLS, Manuel. A Sociedade em rede: a era da informação - economia, sociedade e cultura. Tradução de Roneide Venâncio Majer com a colaboração de Klauss Brandini Gerhardt. 8. ed. São Paulo: Editora Paz e Terra, 2005. v. 1, 698 p.

CARVALHO, Isabel Cristina M. Educação Ambiental: a formação do sujeito ecológico. São Paulo: Cortez, 2004. $256 \mathrm{p}$.

DIAS, Genebaldo Freire. A situação da Educação Ambiental no Brasil é fractal. In: Brasil. Panorama da Educação Ambiental no Ensino Fundamental. Brasília: Ministério da Educação, 2001. p. 71-75.

DOWBOR, Ladislau. Tecnologias do Conhecimento. 2. ed. Petrópolis: Vozes, 2001. 85 p.

LEFF, Enrique. Saber Ambiental. Petrópolis: Vozes, 2002. 343 p.

LEVY, Pierre. As tecnologias da inteligência. São Paulo: Ed. 34, 1993.

LEVY, Pierre. Cibercultura. Tradução de Carlos Irineu da Costa. 2. ed. São Paulo: Editora 34, 2000, (6 ${ }^{a}$. Reimpressão, 2007), 260 p.

MORIN, Edgar. A religação dos Saberes: o desafio do século XXI. Rio de Janeiro: Bertrand Brasil, 2002.

PASSARELLI, Brasilina. Hipermídia na Aprendizagem. Construção de um Protótipo

Interativo: a escravidão no Brasil. 1993. 218f. Tese (Doutorado em Ciências da Comunicação) - Departamento de Cinema, Rádio e Televisão da Escola de Comunicações e Artes, Universidade de São Paulo, São 
Paulo, 1993.

PONS, Juan de Pablos. Visões e Conceitos sobre a Tecnologia Educacional. In: SANCHO, Juana Maria (Org.). Para uma Tecnologia Educacional. Porto Alegre: Artmed, 2001. 327 p.

SANTOS, Milton. A natureza do espaço. Técnica e Tempo. Razão e Emoção. São Paulo: HUCITEC, 1997.

SATO, Michele. Educação Ambiental. São Carlos: Rima, 2004.

SCHAUN, Angela. Educomunicação. Rio de Janeiro: Mauad, 2002.

SILVA, Bento Duarte. A inserção das tecnologias de informação e comunicação. Repercussões e exigências na profissionalidade docente. In: MOREIRA, Antônio Flávio B; MACEDO, Elizabeth Fernandes de. Currículo, Práticas Pedagógicas e Identidades. Portugal: Porto Ed., 2002. p. 65-91.

TRAJBER, Raquel. Educomunicação para coletivos educadores. In: Ministério do Meio Ambiente. Encontros e Caminhos: formação de educadoras(es) ambientais e coletivos educadores. Brasília: MMA/Diretoria de Educação Ambiental, 2005.

TRAJBER, Raquel; COSTA, Larissa B. (Org.). Avaliando a Educação Ambiental no Brasil. Materiais audiovisuais. São Paulo: Fundação Peirópolis/Instituto ECOAR para a cidadania, 2001.

WURMAN, Richard Saul. Como transformar informação em compreensão. São Paulo: Cultura: Editores Associados, 1991. 380 p.

YILDIRIM, Zahide. Hypermedia as a Cognitive Tool: Studente Teachers' Experiences in Learning by Doing. Nova Zelândia, 2005. Disponível em: <http://www.ifets.info/journals/8-2/10.pdf. Acesso em: 02 fev. 2013. 